\title{
AUTOETNOGRAFIAS DE PROFESSORAS DOUTORAS NEGRAS: ESPAÇOS \\ FAMILIARES DE FORTALECIMENTO
}

\author{
Autoetnografías de profesoras doctoras negras: espacios \\ familiares de fortalecimiento \\ Autoethography of afrodescendants phd teachers: spaces for \\ strengthening and solidarity
}

JOSELINA DA SILVA Universidade Federal Rural do Rio de Janeiro (Brasil) joselinajo@yahoo.com.br

MARÍA SIMONE EUCLIDES Universidade Federal de Viçosa (Brasil) simoneeuclides@yahoo.com.br

\section{RESUMO}

A proposta deste artigo é contribuir com os estudos sobre mulher e ciência, provocando uma interseccionalidade entre gênero, raça, geração e uma epistemologia antirracista. A partir de nossos lugares de atuação (universidades públicas e federais), propomos uma autoetnografia negra feminista dialogada, trazendo reflexões para além das vivências diante do racismo e do sexismo. Refletimos a partir do entendimento de que a autoetnografia é um método de pesquisa qualitativa que faz uso dos dados sobre o self e o contexto em que está inserido. Assim, o(a) pesquisador(a) é o centro da investigação, reunindo em si o sujeito e o objeto. Neste sentido, o self (pesquisador/a) e outros selves (os de fora) são reunidos. Em nosso exercício, buscamos que esta metodologia traga duas vozes simultâneas que promovem um enunciado, a partir de experiências individuais ou coletivas, num mesmo texto. Somos duas mulheres negras e doutoras, de gerações diferentes (uma nos seus trinta e outra nos sessenta), que 
ao falar dos racismos múltiplos no âmbito educacional -embora com uma diferença de três décadas- nossas existências ainda guardam muitas semelhanças. Apontamos aqui uma parte das redes de afeto e religiosidade que compõem as nossas travessias, nosso ethos, bem como pertencimento também no âmbito da práxis educacional.

Palavras-chave: autoetnografia, antirracismo, interseccionalidade

\section{RESUMEN}

El objetivo de este artículo es contribuir a estudios sobre la mujer y la ciencia basados en una interseccionalidad entre género, raza, generación y una epistemología antirracista. Desde nuestros lugares de actividad (universidades públicas y federales), proponemos una autoetnografía feminista negra dialogada, llevando reflexiones más allá de nuestras experiencias en el frente al racismo y el sexismo. Reflexionamos desde el entendimiento de que la autoetnografía es un método de investigación cualitativa que hace uso de datos sobre el yo y el contexto en el que se inserta. Así, el investigador es el centro de la investigación que reúne el sujeto y el objeto. En este sentido, el yo (investigador) y otros yoes (los de fuera) se unen. En nuestro ejercicio, buscamos que esta metodología traiga dos voces simultáneas que promuevan una declaración - a partir de experiencias individuales o colectivas - en un mismo texto. Somos dos mujeres negras, doctoras, de distintas generaciones (una en la treintena y otra en los sesenta), que cuando hablamos de múltiples racismos en el ámbito educativo -aunque con una diferencia de tres décadas- nuestras existencias siguen siendo muy familiares como blanco de manifestaciones y performances discriminatorias. Señalamos aquí parte de las redes de afecto y religiosidad que conforman nuestros cruces, nuestro ethos, así como nuestras pertenencias y acciones a las que deben ser referidas como apoyo a la denuncia y lucha antirracista también en el ámbito de la praxis educativa.

Palabras clave: autoetnografía; antirracismo; interseccionalidad. 


\section{ABSTRACT}

The objective of this article is to contribute to studies on women and science based upon an intersectionality between gender, race, generation and an anti-racist epistemology. From our places of activities (public and federal universities), we propose a dialogued Afro-descendant feminist autoethnography, bringing reflections beyond our experiences in facing racism and sexism. We reflect from the understanding that auto-ethnography is a qualitative research method that uses data about the self and the context in which it is inserted. Thus, the researcher is the center of the investigation bringing together, the subject and the object. In this sense, the self (researcher) and other selves (those outside) are brought together. In our exercise, we seek that this methodology brings two simultaneous voices that promote a statement - from individual or collective experiences - in the same text. We are two Afrodescendant women and doctors, from different generations (one in her thirties and another in her sixties), that when talking about multiple racisms in the educational area -although with a difference of three decades - our lives are still very alike, We point here, part of the networks of affection and religiosity that make up our crossings, our "ethos", as well as our belongings and action to which they must be referred as support for the reports and anti-racist struggle, also within the scope of educational praxis.

Key words: autoethnography; anti-racism; intersectionality.

\section{INTRODUÇÃO}

En su mayoría, quienes aún insisten en respaldar las formas canónicas de hacer y escribir investigación están defendiendo el punto de vista del varón blanco, heterosexual, cristiano, de clase media/alta y sin discapacidad. Siguiendo estas convenciones, el investigador no sólo ignora otras formas de conocer, sino que también da por supuesto que ellas son deficientes y no válidas. (Ellis, Adams e Bochner, 2015, p. 252) 
É amparado pela crítica apresentada nesta epígrafe que surge este texto autoetnográfico. Vimos (Simone Euclides e Joselina da Silva) desenvolvendo, há algum tempo (Euclides Silva, 2018; Euclides Silva, 2019), uma metodologia de pesquisa ainda pouco utilizada no campo acadêmico brasileiro, que é a autoetnografia ${ }^{1}$. Embora escassamente presente em português, há uma vasta literatura em língua inglesa e um certo número em espanhol.

Temos nos proposto a fazer uma autoetnografia negra feminista e dialogada (Griffin, 2012; Salters, Jasmine, 2016). Em nosso exercício, buscamos que esta metodologia traga duas vozes simultâneas que promovem um enunciado, a partir de experiências individuais ou coletivas, num mesmo texto. Somos duas mulheres negras e doutoras na América Latina, de gerações diferentes (uma nos seus trinta e outra nos sessenta). Temos observado que ao falar dos racismos múltiplos no âmbito educacional -embora com uma diferença de três décadas- nossas existências ainda guardam muita familiaridade como alvos de manifestações e performances discriminatórias.

A partir de nossos lugares de atuação (universidades públicas e federais), propomos uma autoetnografia negra feminista dialogada, trazendo reflexões para além das vivências diante do racismo e do sexismo. Apontamos aqui uma parte das redes de afeto e religiosidade que compõe as nossas travessias, nosso ethos, bem como pertencimento e ação às quais devem ser referidas como sustentáculo para a denúncia e luta antirracista, também no âmbito da práxis educacional.

\footnotetext{
${ }^{1}$ Como introdução ao tema sugerimos: Autoetnografia: uma alternativa conceitual. (Daniela Versiani, 2002). Bem como o texto: O método da autoetnografia na pesquisa sociológica: atores, perspectivas e desafios. (Silvio Mateus, 2017).
} 
O QUE FALAMOS SOBRE AUTOETNOGRAFIA?

A autoetnografia é um método de pesquisa qualitativa. Para tal, faz uso dos dados sobre o self e o contexto em que está inserido, de forma a promover uma conexão entre este e os outros. É uma metodologia onde o(a) pesquisador(a) está como o centro da investigação, reunindo em si, o sujeito e o objeto. Ou seja, tanto pesquisa como é pesquisado(a). Neste sentido, o self (pesquisador/a) e outros selves (os de fora, sejam similares ou diversos) são reunidos em contextos. Por conseguinte, vários outros estão presentes na narrativa autoetnográfica, (Ngunjiri, Hernandez, y Chang, 2010).

Autoetnógrafos(as) assumem, ao mesmo tempo, papéis tradicionalmente posicionados em campos distintos. Dito de outra forma, são os(as) que narram e aqueles(as) que descrevem e, no mesmo desempenho investigativo, são os(as) que analisam/interpretam. Ao desenvolverem seus estudos, reúnem a pesquisa (grafia), a cultura (através do etno) e o self (auto) com ênfases diversas ao longo dos seus trabalhos. Diferentemente do que aprendemos nos âmbitos tradicionais acadêmicos -onde somos formadas e contribuímos com a formação de nossos(as) discentes- ao utilizar a autoetnografia, observamos que "los investigadores decidem quién, qué, cuándo, dónde y cómo investigar" (Adams et. al, 2015, p. 251). A escrita e a vivência dialogam com um contexto amplo e desafiador onde o individual perpassa um coletivo de múltiplas experienciações e interpretações.

O conhecimento "é intrincadamente conectado com interesses pessoais, as experiências e a familiaridade2" (Ngunjiri; Hernandez; Chang; 2010, p. 2).

\footnotetext{
2 Tradução das autoras: Scholarship is inextricably connected to self-personal interest, experience, and familiarity (Ngunjiri; Hernandez; Chang; 2010, p. 2)
}

INTEREDU № 4 VOL. I (Julio 2021) PÁGs. 99-127 ISSN: 2735-6523| 103 
Assim, as autoras seguem apresentando-se como modelos ilustrativos do que discutem em seus estudos. Como exemplo -no texto com o qual estamos dialogando- as mulheres africanas em posição de liderança, foram alvo das reflexões de Faith Wambura Ngunjiri que é keniana. Outra das escritoras é Kathy-Ann C. Hernandez, nascida em Trinidad e tendo vivido nas Ilhas Virgens Britânicas. Desta forma, dedicou-se a estudar os alunos das High Schools das cidades onde esteve. E finalmente, Heewon Chang, como uma professora de escola secundária, constituiu aí o seu locus de reflexão e análise. Tal fato deu possibilidade para que seus posicionamentos, derivados da mediação entre suas identidades sociais, oportunizassem mudanças que se apresentaram no ambiente acadêmico. Por outro lado, nota-se o protagonismo reafirmado na escrita e pesquisa de, e por mulheres negras, que se situam dentro e fora dos espaços acadêmicos; quer sejam mulheres em posições de lideranças em seus respectivos territórios de pertencimentos, quer sejam nos espaços nos quais atuam como professoras.

Neste sentido, para hacer y escribir autoetnografía, el investigador aplica los principios de la autobiografía y de la etnografía. Así, como método, la autoetnografía es, a la vez, proceso y producto. (Adams et. al, 2015, p. 250). Por conseguinte, a subjetividade e a emoção de quem investiga, bem como sua visão de mundo, vêm a público e contribuem para a complementariedade e contextualização do texto.

Trata-se de uma forma que entende a investigação como um ato político e social, ao lado de ser socialmente consciente. A autoetnografia valese das metodologias utilizadas na autobiografia, bem como as da etnografia (Adams et. al, 2015). Lembram estes autores, que a crise pautada pelo pósmodernismo nos anos oitenta, entre outros desafios, propôs novos paradigmas nas Ciências Sociais. A autoetnografia -naquela conjuntura- a 
presentou-se como uma respuesta positiva a las ideas canónicas acerca de qué es y cómo debería hacerse investigación (Adams et. al, 2015, p. 254). Surge então, uma forma de investigação que, segundo nossas teóricas, permitiu a uma maior acessibilidade e significância onde a experiência pessoal estivesse como a base. Deste modo, tornou-se viável que as questões de identidade política e acontecimentos anteriormente silenciados, ao lado de formas de representação diversas, viessem a ser visibilizados no "fazer investigativo".

Destarte, recorremos (Simone Euclides e Joselina da Silva) à autoetnografia por ser uma forma de autonarrativa, ou seja, o si mesmo no interior de um determinado contexto social. $O$ objetivo aqui é criar um diálogo e reflexões que tangenciam nossos escritos, narrativas teóricas e práticas, enquanto docentes negras em universidades públicas federais, muitas delas advindas das experiências com demais mulheres negras do seio familiar. Buscamos situar ainda, como as nossas interações e relações sociais, efetivadas no cotidiano, ao longo da nossa formação familiar (individual e coletiva), abrem um leque de dispositivos para pensar e reescrever vivências coletivas e encorajadoras, que se refletem nas lidas das professoras universitárias que nos tornamos.

CONSTRUÇÃO DE ESPAÇOS DO SAGRADO NA INFÂNCIA E SUAS INFLUÊNCIAS EM NOSSO FAZER/CONCEBER O ESPAÇO EDUCATIVO

“Se a dominação pode ser inevitável como fato social, é improvável que ela permaneça hegemônica como uma ideologia no interior dos espaços sociais em que as mulheres negras falam livremente. Esse domínio de um discurso relativamente seguro, mesmo que restrito, é uma condição necessária para a resistência das mulheres negras. Famílias estendidas, igrejas e organizações comunitárias, são 
espaços importantes nos quais o discurso seguro potencialmente pode ocorrer. (Collins, 1990, p. 6)

Patrícia Hill Collins, feminista negra afro-estadunidense, ressalta a importância de mulheres reconhecerem as redes de apoio, de afeto, do existir e resistir em seus determinados contextos de vida. Somos atravessadas desde sempre por referências que nos auxiliam no enfrentamento a situações diárias de racismo e sexismo. Em um dos eixos deste espelhamento, podemos situar a ancestralidade viva e pulsante mediante a resiliência das que vieram antes de nós (avós, tias, mães), mulheres negras e suas afirmações cotidianas. Para a autora, o fato de conseguirmos enxergar e valorizar estas redes é o que ajuda a pensar e criar outras narrativas negras de poder e resiliência de maneira coletiva. Assim, destacamos aqui algumas: famílias, espiritualidades, comunidades negras, movimentos de mulheres e de mulheres negras, núcleos de estudos afros, dentre outros.

Esses lugares institucionais nos quais as mulheres Negras constroem autodefinições independentes refletem a natureza dialética da opressão e do ativismo. Escolas, a mídia impressa e os meios de comunicação, agências governamentais e outras instituições do ramo da informação reproduzem as imagens controladoras da condição de mulher Negra. Em resposta, as mulheres negras se utilizaram tradicionalmente das redes familiares e das instituições da comunidade Negra como espaços para se opor a tais imagens. (Collins, 1990, p.7)

Destes lugares e redes de afeto e fortalecimento eu, Simone Euclides, anuncio a minha identidade enquanto mulher negra constituída fisicamente e espiritualmente em uma comunidade negra rural. Trata-se de uma criação em comunhão, entrelaçada de trocas e reciprocidades tão presentes na vizinhança e nas casas sempre cheias durante as refeições 106 | INTEREDU № 4 VOL. I (JuLIO 2021) PÁGs. 99-127. ISSN: 2735-6523 
fartas, rezas e novenas. É importante ressaltar, como o meio rural onde vivi ainda é um território distinto do meio urbano em que me encontro hoje. Nas discussões sociológicas sobre o meio rural, o campo se constitui ainda enquanto um lugar a margem, desprovido dos bens e serviços que são encontrados na zona urbana, como por exemplo: escolas de qualidade, assistência médica e saneamento básico. A “autogestão", os mutirões e a coletividade advêm também da necessidade de resolvermos, por nós, as demandas que deveriam ser resolvidas pela administração pública. Ademais, os laços de familiaridade extrapolam a consanguinidade. Em comum unidade (comunidade), a proximidade das casas, o ir e vir, a certeza do apoio e o companheirismo, constituem nesse espaço um ponto crucial na educação informal em valores como: a justeza, a solidariedade e o "estar juntos" em vizinhança.

Como mencionado acima, embora todos os condicionantes sociais e o devir no meio rural -onde minha família está situada-me foi possível perceber vários aspectos de uma ancestralidade africana como a união, a coletividade, a música -como elemento vital de espiritualidade- e a alegria presente nos espaços de sociabilidade e socialização. Nas famílias negras do meu entorno, eu, Simone Euclides, identifico e presencio que tais elementos existem de maneira conjunta e espontânea nos batuques de domingo, nas celebrações quando a chegada de um ente ou amigo/a querido/a, dentre outros movimentos de reconhecimento dos elos que nos cercam. Todos enriquecidos de uma à outra geração e alinhavados nas imanentes resistências cotidianas de nossas trajetórias - do canto à reza das bisavós e bisavôs às crianças. Falo disso aos meus e minhas discentes procurando estimulá-los/as a recolher em suas comunidades o que lhes possa fortalecer, mesmo que seja de difícil detecção. Reconectar com aquilo que nos constituiu em primeiro lugar enquanto pessoas neste 
mundo: as nossas raízes, sobretudo as maternas, trata-se de um devir, de um enraizamento necessário para nos entendermos nesse âmbito.

Assim, faz-se importante demarcar também o poder da figura feminina, aqui situada pela matriarca da família, um lugar de força e exemplo de resiliência. Situo (eu, Simone Euclides) a minha avó materna - que gestou dezoito filhos (as) e cuidou de boa parte de seus (as), mesmo com parcos recursos econômicos -está presente neste espaço territorial. De modo peculiar, genuíno e sagrado, vovó é benzedeira- dessas que benze pelo bem e para o bem de alguém, sendo os seus ou não. Sempre vi na presença dela, aquele cuidado da mulher negra que agrega, abraça, acolhe a todos (as). Desde sempre se entendeu como a "Mãe Preta", sinônimo da protetora. Com ela, eu tenho apreendido que não se pode brincar com coisa séria. Que o sagrado só é sagrado se realmente for justo, verdadeiramente humano e nos faça seguir de maneira "correta" e reta. Assim ela o proclama.

No ato da benzedura há uma relação de sensibilidade e entrega ao outro através da palavra e/ou do ato de proferir uma benção para alguém. E nessa perspectiva, a oralidade tem papel preponderante enquanto representação coletiva. As benzedeiras -como a minha avó- são portadoras de grande fonte de saberes que são passados hereditariamente para filhos (as), netos (as), sobrinhos (as) e representam elos entre o passado e o presente, demarcando identidades, continuidades e pertencimentos em um dado local. Aqui, a oralidade é o meio e fim de comunicação e valoração das/nas gerações, além de cumprir o seu papel educativo que é formar e informar valores humanistas (cuidado e respeito) para com o próximo; querer bem; querer o bem e, dentro do possível, contribuir para que as relações sejam construídas com base na honestidade, altruísmo, alteridade e bondade. 
Como afirma Giselda da Silva (2014), “é possível observar esta prática com uma íntima relação com o campo e costumes da roça, onde as pessoas diante das dificuldades da vida buscavam solucionar seus problemas com as possíveis alternativas que se apresentavam no cotidiano" (p.6). Assim, como foi constatado na pesquisa realizada por Silva na comunidade remanescente de quilombos em Santana da Caatinga, cidade de João Pinheiro no estado de Minas Gerais, as (os) benzedeiras (os) possuem destaque em suas localidades. São conselheiras, avós, tias e madrinhas que detêm a capacidade de tocar e formar. São mulheres que representam peças-chaves na ambiência onde vivem. São procuradas quando há conflitos, problemas espirituais e emocionais, representando esse aporte espiritual importante no elo da comunidade. Assim era, e segue sendo, minha avó e tantas outras mulheres negras em comunidades rurais.

O conselho, advindo de cada uma delas, pode ser considerado palavra sagrada e está intimamente ligado à importância das trocas efetuadas dentro de uma comunidade nos atos de falar e escutar. A oralidade é ainda hoje o principal meio de transmissão de valores e conhecimentos, no lugar onde cresci. Neste sentido, compreende-se por que a griotte como mestra da palavra, é a agente principal da manutenção da harmonia dentro de uma comunidade. Ao contar histórias, mediar conflitos e dar conselhos, a griotte é o elo maior desta cadeia familiar (Bernat, 2013, p. 31). Ademais, as dimensões acima citadas, perpassam concepções da filosofia africana, na qual se tem na coletividade e no diálogo, o respeito e a valorização dos saberes ancestrais, um dos pontos marcantes para se pensar como as comunidades negras, e a maneira com a qual as mulheres constroem e reconstroem ramificações de força e vida de geração em geração, educando e reeducando para relações mais 
humanas e humanizadas, apesar de contextos onde ainda pairam o racismo e o patriarcado.

Assim é a minha avó, que reúne em si a dinâmica da fala e escuta, a troca com o outro e nos faz pensar nas várias maneiras de se tocar o próximo com o olhar, com gestos e não somente com as palavras ditas. Em conversas, ela sempre me diz que somos seres em comunidade; sozinhos não somos nada e que é preciso sempre andar com justeza, seriedade e verdade. Priorizo transportar esses saberes adquiridos também para o plano profissional, em termos de diálogo com minha própria práxis acadêmica, durante os anos de docência, pesquisas e vivências na área da Educação do Campo. Eu, Simone Euclides, atuei no período de 2015 a 2020. Neste fazer/conceber o processo educativo, carrego comigo partes desta raiz cuja ramificação tem a minha avó como sustentáculo e exemplo de mulher, mãe e educadora, ainda que ela seja analfabeta ${ }^{3}$.

Atuando nas disciplinas de Relações Raciais e de Gênero, sempre que entrava na discussão sobre racismo e sexismo, era comum estudantes narrarem situações nas quais o racismo atravessou as suas experiências de vida. Foi o caso de Helena ${ }^{4}$, que narrou cenas de sua infância e adolescência na escola, as situações de discriminação racial vividas ao longo de sua escolarização; circunstâncias que antes das aulas sobre relações raciais ela não reconhecia como racismo.

Posterior às aulas e diante de uma nova ancoragem teórica para pensar as suas respectivas realidades, traziam estratégias de desconstrução das desigualdades raciais e de gênero. Ou seja: possibilitar

\footnotetext{
${ }^{3}$ Hoje aos 81 anos, minha avó ressalta a importância dos estudos. De uma época em que o patriarcado marcava o cenário das famílias, minha avó não teve a oportunidade de sair de casa para estudar. Ainda hoje ela reconhece a importância do saber ler e escrever. Seus olhos saltam quando me vê contar de minhas experiências em sala de aula.

${ }^{4}$ Nome fictício.

110 | INTEREDU № 4 VOL. I (JULIO 2021) PÁGS. 99-127. ISSN: 2735-6523
} 
novas lentes, modos de enxergar e intervir na realidade subjetiva e objetiva. Helena, enquanto também um educadora na fase do maternal, repensou a sua prática pedagógica e passou narrar experiências de combate ao racismo em sua sala de aula, na creche onde atuava, tornandose assim uma agente na luta antirracista no espaço escolar.

Do mesmo modo, no respectivo espaço de docência, eu e as/os discentes comungamos, via atividades de pesquisa e intervenções, temáticas diretamente relacionadas ao trabalho com as identidades, memórias e agenciamentos do cotidiano. São textos, livros, atividades com foco direcionado ao conhecer/saber/ser de um mundo diferente, em prol de compreensões a partir das totalidades e opressões que nos afetam, reconhecendo-as e se libertando das mesmas.

Diferentemente, eu, Joselina da Silva, por ser de outra geração, a caminho dos setenta anos, não consigo traçar uma linha tão extensa de mulheres negras, no seio da família biológica. Tenho minha avó materna, Maria Ambrósia -sobre quem já referi em outros textos e poderia seguir falando sem o risco da repetição (Silva, 2019)- Tia Celina, filha dela, e Tia Marina, a nora que se tornou filha. Minha avó, suas duas filhas e dois filhos são naturais de Senador Firmino (MG). Fazem parte do grande fluxo de imigrantes mineiros que aportaram no Rio de Janeiro nos anos cinquenta. Fui àquela cidade uma vez, durante minha adolescência. Ali, minha mãe me ensinava que, embora pobres, viajar se constituía num sonho possível.

Surpreendi-me ao chegar à universidade como professora e descobrir um incontável número de jovens negros e pobres que jamais haviam saído de suas cidades ou se aventurado numa viagem, ainda que breve. São batalhões de pessoas cuja visão de mundo pode se manter estreita, por não terem o direito de conhecer e experienciar realidades diversas das suas. Encontrei alunos(as) que nunca haviam visitado a 
capital do Estado, embora residindo na Baixada Fluminense que dista, no máximo, três horas do centro da cidade do Rio de Janeiro. Desta forma, vamos sendo apartados desde tenra idade. Tenho, então, envidado esforços, os mais diversos, para que os alunos que estejam em meu entorno, possam adquirir hábitos e vivências de trafegar por estações, estradas e aeroportos ${ }^{5}$. Fazendo-o de forma crítica e analítica para alongarem seus olhares sem perder as raízes de onde vieram. Neste sentido, viagens de estudos, congressos e eventos acadêmicos diversos são trazidos ao âmbito de seus interesses.

Ambas (Simone Euclides e Joselina da Silva), reafirmamos que a educação pode vir a ser um dos caminhos cruciais na reeducação de nossas posturas, condutas e ações. No entanto, para isso, é preciso desnaturalizar a realidade, quer seja no campo ou na cidade. Cada vez mais, inquietar mentes e assim, prosseguirmos em uma perspectiva coletiva, sensível e capaz de se "revoltar", contra as injustas, maneiras de silenciamento, invisibilidade e epistemicídio. Pensando assim, temos buscado --no exercício da docência- através de um caminho dialógico, incentivar reflexões críticas e ao mesmo tempo denunciar que racismos e

\footnotetext{
${ }^{5}$ Durante a realização de meu pós-doutorado, em 2019 (que abordou a questão do movimento de mulheres negras na Argentina, Peru e Uruguai), uma das viagens consistia em visitar as cidades de Melo, Rivera e Artigas, interior do Uruguai e fronteira com o Brasil. Fui acompanhada, naquela oportunidade, das alunas Fabrícia do Nascimento Silva de Oliveira, Suelen Pereira Estevam da Silva e Luziara Miranda Novaes (à época concluintes do curso de mestrado no Programa de Pós Graduação em Educação contextos Contemporâneos e Demandas PopularesPPGEDUc, Universidade Federal Rural do Rio de Janeiro) residentes no Rio de Janeiro. Durante quinze dias de viagem, elas tiveram a oportunidade de encontrar com antigos ativistas do movimento negro brasileiro e de organizações sociais como aconteceu na cidade de Porto Alegre (Brasil). Já no Uruguai, não apenas acompanharam minhas entrevistas nas três cidades, como puderam visitar grupos culturais, grupos sociais, entidades e organizações educacionais das cidades visitadas.
}

112 | INTEREDU № 4 VOL. I (JULIO 2021) PÁGs. 99-127. ISSN: 2735-6523 
sexismos têm sido basilares no processo formativo de educadores(as) e educandos(as), no espaço da sala de aula e fora do ambiente acadêmico. Propondo assim, uma educação transgressora como nos propõe (Hooks, 2013).

Quanto ao meu sagrado -Joselina da Silva-, este foi constituído no som, diferentemente de Simone Euclides. Silêncios eram os menos percebidos nos momentos de reza. Fui criada na tradição das religiões de matriz africana. Sou do candomblé, como afirmamos no Brasil. Minha casa era um dos múltiplos centros religiosos (terreiro)-constituídos desde os anos cinquenta- nas periferias da capital do estado do Rio de Janeiro. Ouvia minha mãe pedindo para alguma filha ou filho de santo: - Olha Exu ela está fazendo esta oferenda porque deseja tal graça! Olha Exu! afasta dela as negatividades, as maledicências, as invejas, em nome do (a) Orixá... (e dizia o nome da entidade invocada naquele momento). Palavras que eram ditas em voz alta. Em seguida, cantos, palmas e atabaques ressoavam e eram entoados pelas pessoas presentes dando movimento ao sagrado. Não rezávamos -ainda não o faço-em silêncio.

Sempre fui aluna travessa, durante o antigo ensino ginasial. $\mathrm{Na}$ escola, escoava a ausência de irmãs -sou filha única- numa casa repleta de adultos (todos ligados a casa de axé) e poucas crianças. Assim, chegava ao final do ano letivo necessitando nota máxima em quase todas as matérias do currículo. Em minha classe social e tempo estudantil, não havia o(a) professor(a) explicador(a). Logo, deveria sozinha estudar, entender e ser aprovada em um mês no período de recuperação. Neste momento, entrava minha mãe com seu conhecimento sobre a ancestralidade. Saíamos de casa nas primeiras luzes de um determinado dia, e íamos a um local de mata fechada. Éramos apenas nós duas a fazer

\footnotetext{
${ }^{6}$ Para maiores informações sobre Exu, sugerimos : Exu do Brasil: tropos de uma identidade afrobrasileira nos trópicos Disponível em: https://www.jstor.org/stable/43923870
} 
oferendas aos Orixás e assim constituíamos um segredo sagrado. Vários pratos eram oferecidos e calmamente depositados um a um. Cada entrega era acompanhada por uma reza/cantiga entoada por minha mãe e seguida por mim.

Kayode Olusola ${ }^{7}$, analisando as crianças Oyo-Yoruba da Nigéria, observa que em qualquer das comunidades dos Yorubás, a música tem diferentes valores socioculturais. Ela pode, além de ter função religiosa/ritual, ser empregada nos festivais, ser diversão -em diferentes esferas- bem como ser utilizada como meio educacional. Na mesma direção, Oludare (2018), também estudando a sociedade Yorubá, reitera que a música de um povo tem uma tripla função, que é preservar, exibir e desenvolver a herança musical e cultural. O Brasil tem uma longa tradição das religiões de matriz africana. Igualmente, minha mãe -como uma yalorixás- transformava aquelas manhãs em oportunidades pedagógico-educacionais quando ensinava que minha formação escolar e o sagrado estavam conectados. Eram momentos em que, através do call and response (chamada e resposta), minha mãe cantava e eu respondia8, trazíamos a música, na saudação aos Orixás.

Performava-se assim, a dupla maternidade. A Yalorixá que invocava o sagrado em socorro a uma filha em necessidade, e a Dona Durvaliana, minha mãe, cuidando da educação de sua cria. Voltávamos já no início da tarde, almoçávamos e eu retornava aos estudos com maior segurança.

\footnotetext{
${ }^{7}$ Functions of Children Satirical Songs: The Oyo-Yoruba experience By Kayode Olusola. Disponível em:

https://www.academia.edu/29830849/Functions_of_Children_Satirical_Songs_The_OyoYoruba_exp erience

${ }^{8}$ Sobre chamada e resposta (call and response) sugerimos a leitura de Poesia negra, jazz e capoeira: o canto, a performance e a memória do corpo. Prof. Dr. Elio Ferreira de Souza (2011). Disponível em: http://www.abralic.org.br/eventos/cong2011/Anais 114 | INTEREDU № 4 VOL. I (JULIO 2021) PÁGS. 99-127. ISSN: 2735-6523
} 
Afinal, agora já não estava só. Tinha um professor explicador direto dos ensinamentos ancestrais e de fé, adquirido em casa. O qual atravessou o Atlântico e materializou-se em Duque de Caxias na Baixada Fluminense, Rio de Janeiro.

No ano seguinte, os(as) colegas de sala eram tomados(as) de surpresa ao ver-me adentrar no recinto. Haviam terminado o ano certos de que eu seria reprovada. Consideravam impossível superar todas as provas que me aguardavam. Durante anos de minha adolescência, vi minha mãe devotamente preparar e me ensinar a "conversar" com aquele orixá. Logo, a ele e a ela, devo o fato de ser pós-doutora hoje.

Destarte, nossos aprendizados no âmbito do sagrado, seja no catolicismo com forte influência tradicional africana (como no caso da avó benzedeira/Griotte de Simone Euclides), ou na religiosidade de matriz africana (como realizada pela mãe de Joselina da Silva), seguem instruindo nossas práxis acadêmicas ao termos escutas e falares com nossos discentes, e ao governar nossas escolhas por temas, fontes teóricas e metodologias, onde olhares sobre as questões das relações raciais sejam privilegiados, ao lado da reflexão sobre o antirracismo. Neste sentido, muito tem nos ajudado a promulgação da Lei 10.639/03, que institui a obrigatoriedade do ensino de história e cultura africana e afro-brasileira nas escolas públicas e privadas de ensino fundamental e médio, em âmbito nacional. A existência do referente texto legal nos dá amparo para compartilhar pedagogicamente, nossas experiências como mulheres negras e professoras, de forma a incentivar nossos (as) alunos (as) a perceberem nos ensinamentos familiares, fontes e formas estratégicas contra as diferentes expressões de racismo e sexismo. Ajudá-los (las) a perceber a importante referência que pode ser encontrada nas vivências pessoais e familiares. 
Joselina Da Silva y María Simone Euclides

SAIR DO ACOLHIMENTO: A CHEGADA DE ESCOLA E DO RACISMO

Num texto publicado há mais de duas décadas, Munanga (1996) chamava atenção para uma das peculiaridades do racismo no Brasil. O autor utiliza-se do resultado da pesquisa da Folha de São Paulo (Turra e Venturini, 1995), onde a maioria dos(as) entrevistados(as) afirmou não ser racista, mas, conhecia alguém que o fosse. Este estado de coisas, segundo a autor, deve-se ao mito da democracia racial que contribui com um silenciamento sobre o tema e, por conseguinte, dificulta quaisquer debates em seu oposto. É neste ambiente, que a chegada no cenário escolar pode se constituir em ingresso num mundo racialmente hostil para crianças negras brasileiras (Gomes, 2000).

Neste sentido, podemos trazer aqui as reflexões de Giralda Seyferth (1995) quando afirma: "A cor e a forma dos cabelos e dos olhos, a estatura, diversos índices cranianos e faciais, o peso e o volume do cérebro, entre outros traços fenotípicos, também serviram às distinções raciais realizadas desde o século XIX" (p. 176). Embora referindo-se em seu trabalho às metodologias científicas de estudiosos daquele século, estes ideários seguem vigentes no cotidiano da sociedade, manifestando-se de forma cruel contra estudantes, nos diferentes momentos de sua formação, contando, em muitos casos, com a cumplicidade silenciada dos educadores e demais autoridades educacionais.

A saída do seio familiar (cuidado, afeto e cumplicidade) para o espaço escolar, trata-se muitas vezes de passagens dolorosas. Desde a Educação Infantil, na percepção de ser negro(a), somos confrontados com os mais diversos apelidos tais como: $\operatorname{macaco}(a)$, sujo(a), cabelo de Bombril, crioulinho(a), neguinho(a), fedido (a), dentre outros. Estas violências são constantes até ao Ensino Médio. Conforme nos lembra Gomes (2004), crianças negras convivem desde cedo distantes de uma identidade 116 | INTEREDU № 4 VOL. I (JULIO 2021) PÁGS. 99-127. ISSN: 2735-6523 
positiva sobre si e os seus (Gomes, 2000). Embora tenhamos tido avanços no que concerne a políticas afirmativas como por exemplo a Lei 10.639/2003, que torna obrigatório o ensino da História da África e afrobrasileira nas escolas, suas aplicabilidades estão muito aquém do imaginado e esperado.

Comigo (Simone Euclides), que entrei na escola aos seis anos no início dos anos noventa, não foi diferente. O racismo segue pouco ou quase nada explorado e problematizado por aqueles que compõem o cotidiano escolar. E, quando ocorre, ainda é realizado por algumas pessoas que se "solidarizam com a causa". Confundimos, enquanto estudantes, se de fato trata se de uma vivência racista ou se é algo que faça parte da nossas "cabeças". Crescemos com essa dúvida ao passo que experienciamos situações de "preterimento", insegurança, timidez, baixa autoestima e, nos casos mais críticos, abandono da escola. Dito isto, conviver com o racismo e afrontá-lo são experiências, desde sempre, presentes nas nossas trajetórias.

Ainda tenho memória (eu, Simone Euclides) de um fato ocorrido em minha infância escolar que também tenho visto reafirmado por crianças na atualidade. Durante a época das festas juninas na escola, raríssimas são as vezes que meninas negras são convidadas para serem a "noiva" da quadrilha9 . Situação naturalizada há tempos, e interiorizada por cada criança negra como uma atitude de indiferença, influenciando em uma construção negativa sobre elas ${ }^{10}$. Por conseguinte, as marcas subjetivas podem interferir na construção de identidades positivas, seguras e autônomas.

9 O documentário Vista a Minha Pele, é um interessante curta que apresenta as situações de racismo no cotidiano da escola de forma didática e crítica. Disponível em: https://www.youtube.com/watch?v=LWBodKwuHCM

10 Ver Eliane Cavalleiro: Do silêncio do lar ao silêncio Escolar.

INTEREDU № 4 VOL. I (Julio 2021) PÁGs. 99-127 ISSN: 2735-6523| 117 
Quanto a mim, Joselina da Silva, por ter quadris largos, a questão se dava através da referência ao meu corpo, alvo de chacota de meus colegas de escola, principalmente quando no regresso a casa, onde era perseguida notadamente pelas meninas. Queriam ver se eu vestia algum enchimento para aumentar o volume das nádegas. Eram momentos de muita tensão. A eficácia do racismo se dá de forma diretiva, objetiva e subjetiva, no que tange as aspirações e projetos de vida de jovens negros e negras. Do ensino médio ao ensino superior, muitos negros e negras ficam com suas formações inconclusas. Um dos fatores que concorrem para esta interrupção é a ideia já incutida de que são incapazes de prosseguir. Outra, é que a faculdade não é para negros. Há ainda, a necessidade objetiva de ter que ingressar precocemente no mercado laboral, sem tempo para pensar ou sonhar com uma formação superior, ou posterior a ela.

Aos que alcançam o ensino superior, outros dilemas lhes são apresentados. A maioria tem dificuldades em conciliar às necessidades materiais, pois muitas vezes os(as) estudantes são arrimos de família. Para boa parte da população negra e pobre no Brasil, a escolarização ainda é um espaço importante de formação e de ampliação de horizontes profissionais. Assim foi comigo (Simone Euclides), na construção das minhas travessias e trajetórias. Embora reconhecendo que ter um diploma não corresponda diretamente ao ingresso no mundo do trabalho, mediante o "capital cultural e escolar ${ }^{11 "}$ ". Isso porque a chancela de empregabilidade pode ser carregada de critérios subjetivos, nos quais estereótipos e marcadores da existência como raça, gênero, faixa etária e sexualidade, podem influenciar diretamente na contratação ou não dos indivíduos.

\footnotetext{
${ }^{11}$ Sobre capital cultural e escolar ver Bourdieu, em Razões práticas: Sobre a teoria da ação; e Maria Alice Nogueira, em Escritos da Educação.

118 | INTEREDU № 4 VOL. I (JULIO 2021) PÁGS. 99-127. ISSN: 2735-6523
} 
Para mim (Simone Euclides), a escolarização era o caminho de possibilidades para trabalho e renda. Queria ser professora e não sabia ao certo como era o processo para me tornar docente, mas desde criança já queria "ajudar a alfabetizar e dar aula". Os primeiros contatos deram-se nas aulas de reforço para as crianças da minha comunidade, seguida da alfabetização de meus familiares (tios e tias), depois na educação de jovens e atividades na creche -ambas em Viçosa (MG)- até o ingresso como docente no ensino superior.

Meu ingresso (Joselina da Silva) no mundo do trabalho, se deu através da docência num curso de Inglês, na cidade onde morava. Eu acabara o ensino médio e fui convidada a lecionar na filial de uma importante rede de ensino. Era o resultado de três anos de estudos na língua estrangeira, possibilitados por uma bolsa parcial. Meus/minhas alunos(as) adultos(as), eram integrantes da classe média da cidade. Uma de minhas alunas era professora na universidade onde eu recém ingressara, como estudante. Tínhamos uma amistosa relação nas aulas, o que não impediu que ela deixasse de me reconhecer quando nos cruzamos no corredor da universidade. Acompanhada de algumas amigas, fingiu não me ver -uma jovem negra de cabelo estilo black powercomo sua professora. Passadas quase cinco décadas, ainda experimento momentos semelhantes com alunos ou colegas professores, nos ambientes onde sou docente.

\section{EXERCÍCIO DA DOCÊNCIA: ENFRENTAMENTO AOS RACISMOS DO COTIDIANO}

De acordo com a reportagem do jornal Gênero e Número, de 20 de junho de 2018, existe no Brasil 219 doutoras e professoras pretas, atuando em cursos de pós-graduação. Além disso, mulheres pretas com doutorados na docência superior são unicamente $0,4 \%$ deste universo. $\mathrm{Na}$ dimensão, mulheres pretas e pardas com doutorado - que forma o grupo 
das negras - não chegam a 3\% do total de docentes. Entretanto, são recorrentes as perguntas que ambas (Joselina e Simone) ouvimos nas conversas inquietas, questionadoras e interessadas em entender nossas trajetórias acadêmicas: como você conseguiu isso?; Quem abriu o caminho para você?; Você leciona o que mesmo?, entre muitas outras assemelhadas.

O racismo é estruturante das relações sociais. E se efetiva de forma às vezes discreta, e ao mesmo momento agressiva, quando nos fazem lembrar -em momentos do cotidiano- que alguns lugares onde atuamos não são nossos. Uma das características desta realidade, deve-se ao círculo infindável do racismo institucional presente no âmbito do ensino superior -tal como em outros espaços- e seus mecanismos.

Exerço (Simone Euclides) à docência desde 2013. Nasci em Minas Gerais. Migrar e residir em outros estados (Ceará e Piauí) para estudar e trabalhar, me fizeram entender como as relações raciais são fluidas, distintas e com um racismo dimensionado em várias performances. $\mathrm{Na}$ universidade, convivo com as situações mal-entendidas, da percepção de minha corporeidade negra, lida, decifrada e percebida desde os olhares inquietos, às perguntas sobre quem sou, de onde sou, como cheguei ali (aqui) e porque estou ali (aqui). Narrar a minha presença de mulher e professora negra, torna-se quase um devir a ser e a justificar-me, nas ausências de docentes negros(as) no ensino superior. No tempo vivido em Fortaleza- Ceará, muitos perguntavam de qual região da África eu vim. Quando digo que sou brasileira, rapidamente respondem: "Ah então é baiana!". Não deixo de ser africana ou baiana. Mas, fico me perguntando por que pensam que só existem pessoas negras nessas duas regiões.

Eu, Joselina da Silva, nascida na Baixada Fluminense, no Rio de Janeiro, de mãe mineira e pai baiano, sou negra de pele escura, num tom ligeiramente mais claro que Simone Euclides. Durante os anos que residi 
no Ceará, (2006 a 2015) também era questionada sobre minha baianidade. Os cearenses, que tenho encontrado no Rio de Janeiro, onde resido, permanecem com a mesma interrogação. Nunca fui africana, para aquele grupo de residentes. Mas era "americana" diante do meu cabelo estilo rastafári. Era assim estrangeirada, no país onde nasci.

Grada Kilomba (2019), diz que estas atitudes explicitam uma relação de poder. Trata-se de fixar identidades, lugares e não-lugares em uma sociedade que vive uma relação intrínseca entre raça, racismo e territorialidade. Ao perguntar quem sou eu, de onde eu vim, subentendese um lembrete de onde deveríamos estar, o que também demarca que aquele espaço não é o nosso local de pertencimento, nem de realização de cidadania. Com efeito, comungam com o silenciamento e o pacto com o narcísico, de que nos fala Maria Aparecida da Silva Bento (2002), e associado ao racismo institucional em uma universidade onde em seu quadro, poucos(as) são os (as) docentes negros e negras.

Atualmente, sou (Joselina da Silva) professora de uma universidade que está com mais de um século de existência, no Rio de Janeiro. Casos de racismo têm sido reportados por alunos(as), relatados em pequenos grupos, por professores(as) negros(as), além de não negros(as) aliados(as) à uma práxis antirracistas. Temendo ser alvo direto da mesma situação, quando necessito recorrer pessoalmente a algum setor da instituição, antes mesmo de cumprimentar a pessoa a qual devo me dirigir, faço minha apresentação: "sou (Joselina da Silva), professora desta casa de ensino". Determino imediatamente meu lugar de atuação naquele mundo inóspito. Ainda assim, quando necessitei circular por diversos setores para dar prosseguimento aos trâmites relativos à minha licença pós doutoral, era difícil fazer compreender que não era para o doutorado e sim para o estágio seguinte. Inúmeras vezes, via-me obrigada a repetir e corrigir a pessoa a qual eu me dirigia, embora fosse um(a) profissional 
sobejamente habituado(a) a realizar aquelas providências burocráticas. É o fantasma do racismo assombrando a cada instante do fazer laboral.

\section{CONCLUSÃO}

Neste artigo, ao autoetnografarmos um pouco daquilo que somos, do que nos tem constituído enquanto Simone Euclides e Joselina da Silva, propomos promover uma reflexão de quais foram e têm sido os processos de agenciamentos, formação e constituição enquanto mulheres e negras, professoras e doutoras. Reconhecemos os momentos de acolhimento familiar e a presença de mulheres negras no campo e na periferia de uma cidade. Antes de sermos professoras universitárias, somos mulheres negras, filhas e netas de pretas fortes, de sabedoria e conhecimento da vida. Só somos porque elas são, antes de qualquer título adquirido por nós! Fomos/somos educadas por essas mães/mãos negras rompendo a cada década um século de opressões que o processo escravocrata apartou.

As tessituras, embora pessoais, transversalizam dimensões macro das desigualdades existentes em nosso país, que abarcam e afetam de sobremaneira a vida de boa parte das mulheres negras, a saber, racismo e sexismo. Discorrer e refletir sobre esses marcadores em um diálogo autoetnográfico, possibilita trazer à tona, reflexões e ações para desnaturalizar as desigualdades dentro e fora dos espaços acadêmicos. Falar sobre estes temas pode ajudar a desanuviar a ideia da igualdade de direitos, nos agenciando também a pensar estratégias concretas para que de fato consigamos formas igualitárias de viver as nossas humanidades.

Percebemos que as escrituras, narradas a partir de nossos corpos atuantes no mundo, nos ajudam a repensar lógicas de dominação e, do mesmo modo, refletir e valorizar nossas conquistas e superações em diálogos coletivos. Autoetnografar é, ao mesmo tempo, entender a nossa 
corporeidade no mundo -ressaltando a força dessa corporeidade em um país desigual- na primeira pessoal do singular e no plural. Eu e nós.

Mesmo em gerações diferentes, a dimensão do racismo impacta de maneira direta em nossas trajetórias. Torna-se relevante lembrar dos percalços que atravessam o "ser negra no Brasil". Embora todo o contexto de afeto e cuidado que sempre nos cercaram no seio familiar, muitas são as dificuldades enfrentadas pelas pessoas negras no país. A cor da pele ainda pode ser um peso de dor para os/as negros e negras. Portanto, tornar-se negro(a) no Brasil -no sentido em que nos fala Neuza Santos Souza (1990)- é um caminho repleto de obstáculos. Infelizmente, ainda precisamos falar sobre racismo e, provavelmente, abordar este tema por um longo tempo.

\section{REFERÊNCIAS BIBLIOGRÁFICAS}

Adams, T., Ellis, C., \&, Jones, S. (2015). Autoethnography: understanding qualitative research series.

New York, USA: Oxford University Press.

CEERT. (23 de Agosto de 2011). Vista minha pele [Archivo de Vídeo] Youtube. Recuperado de: https://www.youtube.com/watch?v=LWBodKwuHCM

Bento, M. A. S. (2002). Branqueamento e branquitude no Brasil. [Archivo PDF]. Recuperado de http://www.media.ceert.org.br/portal3/pdf/publicacoes/branqueamento-e-branquitude-no-brasil.pdf Bernat, I. (2013). Encontros com o griot Sotigui Kouyaté. Rio de Janeiro, Brasil: Pallas.

Bourdieu, P. (1996). Razões Práticas: sobre a teoria da ação. Campinas, Brasil: Papirus Editora.

Cavalleiro, E. (2012). Do Silêncio Do Lar Ao Silêncio Escolar: Racismo, Preconceito E Discriminação Na Educação Infantil. São Paulo, Brasil: Contexto. 
Collins, P. (2013). Pensamento feminista negro: conhecimento, consciência e a política do empoderamento. [Archivo PDF]. Recuperado de https://edisciplinas.usp.br/pluginfile.php/4123078/mod_resource/c ontent/1/Patricia\%20Hill\%20Collins.pdf

Ellis, C, Adams, T. y Bochner, A. (2015). Autoetnografia: un panorama. Astrolabio, (14), 249-273.

Ferreira, L. (18 de junho de 2018). Menos de 3\% entre docentes da pósgraduação, doutoras negras desafiam racismo na academia. Gênero e número. Recuperado de http://www.generonumero.media/menos-de-3-entre-docentesdoutoras-negras-desafiam-racismo-na-academia/

Gomes, N. (2000). Superando o Racismo na Escola [Archivo PDF]. Recuperado http://portal.mec.gov.br/secad/arquivos/pdf/racismo_escola.pdf

Griffin, R. (2012). I AM an Angry Black Woman: Black Feminist Autoethnography, Voice, and resistance. Women's Studies in Communication, 35(2), 138-157. . Recuperado de https://doi.org/10.1080/07491409.2012.724524

Hooks, B (2013). Ensinando a Transgredir- a educação como prática de liberdade. Tradução de Marcelo Brandão Cipolla. São Paulo, Brasil: Editora WMF Martins Fontes.

Kilomba, G. (2019). Memórias da plantação: episódios de racismo cotidiano. Rio de Janeiro, Brasil: Cobogó. Munanga, K. (1996). Estratégias e políticas de combate à discriminação racial. São Paulo, Brasil: USP; Estação Ciência.

Ngunjuri, F., Hernandez, K. \& Chang, H. (2010). Living Autoethnography: connecting life and research [Editorial]. Journal 
of Research Practice, 6 (1), Artículo E1. Recuperado de http://jrp.icaap.org/index.php/jrp/article/view/241

Oludare, O. (2018). Compositional Techniques in Apala Music. Nigerian Theatre Journal,14(1), 86-107. Recuperado de https://www.academia.edu/37636245/_Compositional_Techniques _in_Apala_Music_In_A_Akoh_Ed_Nigerian_Theatre_Journal_14_ 1_86_107

Pereira, A. (2007). Quem Não Pode Atalhar, Arrodeia!": Reflexões Sobre o Desafio da Práxis dos Educadores dos Agentes Da Lei 10.639/03. 30ª Reunião Anual da ANPED [Archivo PDF]. Recuperado de http://30reuniao.anped.org.br/trabalhos/GT21-3775--Int.pdf

Queiroz, D. (2001). Raça, Gênero e Educação Superior [Archivo PDF] Recuperado http://www.cdi.uneb.br/site/wpcontent/uploads/2016/01/deocele_ mascarenhas_queiroz.pdf

Santos, S. M. A. (2017). O método da autoetnografia na pesquisa sociológica: atores, perspectivas e desafios. PLURAL, 24(1), 214-241. - Recuperado de https://doi.org/10.11606/issn.21768099.pcso.2017.113972

Salters, J. (2016). Touching Paranoia: a black feminist autoethnography on race, desire, and erotic massage. Publicly Accessible Penn Dissertations. . Recuperado de https://repository.upenn.edu/edissertations/2563

Da Silva, G. S. (2015). O significado cultural das benzeoes em uma comunidade remanescente de quilombo (MG). [Archivo PDF]. Recuperado de https://www.encontro2014.historiaoral.org.br/resources/anais/8/13 98901127_ARQUIVO_ARTIGOTEREZINA2.pdf

Ferreira de Souza, E. (2011). Poesia negra, jazz e capoeira: o canto, a performance e a memória do corpo. XII Congresso Internacional da 
Associação Brasileira de Literatura Comparada. . Recuperado de https://abralic.org.br/eventos/cong2011/AnaisOnline/listaresumos. htm

Souza, N. S. (1990). Tornar-se negro ou as vicissitudes da identidade do negro brasileiro em ascensão social. Rio de Janeiro: Graal.

Simone Euclides, M. y da Silva, J. (2019) Dialogando autnoetnografias negras: intersecções de vozes, saberes e prácticas docentes. Práxis Educaciona7, 15(32), 33-52. DOI: 10.22481/praxis.v15i32.5042. Recuperado de https://periodicos2.uesb.br/index.php/praxis/article/view/5042

Simone Euclides, M. y da Silva, J. (2018). De estudantes a professoras universitárias: docentes negras construindo práticas de enfrentamento ao racismo. In Congresso Brasileiro de Pesquisadores Negros. Uberlândia. 2018. Recuperado de https://www.copene2018.eventos.dype.com.br/resources/anais/8/1 532898649_ARQUIVO_Textocopenefinal.pdf

Turra, C. \& Venturi, G. (1995). Racismo cordial. São Paulo, Brasil: Ática.

Versiani, D. B. (2013). Autoetnografia: uma alternativa conceitual. Letras De Hoje, 37(4). Recuperado de https://revistaseletronicas.pucrs.br/ojs/index.php/fale/article/view/ 14258

Olusola, K. Functions of Children Satirical Songs: The Oyo-Yoruba experience [Archivo PDF]

Recuperado de https://www.academia.edu/29830849/Functions Seyferth, G. (2018). A invenção da raça e o poder discricionário dos estereótipos. Anuário Antropológico, 18(1), 175-203. Recuperado de https://periodicos.unb.br/index.php/anuarioantropologico/article/v iew/6581 
Da Silva, J. (2019). Meu Baobá Genealógico: histórias e memórias de mulheres que me sustentam. Revista

Docência e Cibercultura, 3(3), 263-270. Recuperado de https://doi.org/10.12957/redoc.2019.46914 